\title{
HIGH-RESOLUTION AND LOW TEMPERATURE TEM STUDY OF SUPERCONDUCTING CUPRATES AND CMR-MANGANITES YOSHIO MATSUI
}

National Institute for Materials Science, Tsukuba, Ibaraki 305-0044, Japan.

After the discovery of high-Tc cuprate in $1986^{1)}$ as well as CMR-manganite in $1993^{2)}$, we have developed the following different types of TEMs to examine "strongly-correlated transition metal oxides"; (1) 1.3MV high-voltage TEM (H-1500) with $1 \AA$ resolution $^{3)}$, (2) $300 \mathrm{kV}$ analytical TEM (HF-3000S) with FEG and GIF, and (3) 300kV Lorentz TEM with FEG and external magnet up to $300 \mathrm{G}$ at the specimen. In the field of high-Tc superconductors, we have mainly examined the structures of new compound by HRTEM ${ }^{4,5}$. In the field of magnetic materials, we examined the charge-ordered superstructures and ferromagnetic domain structures formed at low temperature (typically below $150 \mathrm{~K}$ ) in various manganites ${ }^{6,7)}$. Here, we present two examples of recent application of our three TEMs to superconductors and magnetic materials.

1. Order/Disorder of $\mathrm{CO}_{3}$ (partly $\mathrm{NO}_{3}$ ) Groups in Oxycarbonitrate Superconductors ${ }^{5)}$

A series of new oxycarbonitrate superconductors, $(\mathrm{Cu}, \mathrm{C}, \mathrm{N}) \mathrm{Sr}_{2} \mathrm{Ca}_{\mathrm{n}-1} \mathrm{Cu}_{\mathrm{n}} \mathrm{O}_{\mathrm{y}}(\mathrm{n}=1$ to 6), prepared under high-pressure of 5 to $6 \mathrm{GPa}$, are examined by high-resolution TEM. Ordered arrangements of $\mathrm{Cu}$ and $\mathrm{C}(\mathrm{N})$ are observed in the compounds with $\mathrm{n}=1$ to 4 , while almost random arrangements for those with $n=5$ and 6 . In the first two members, $(\mathrm{Cu}, \mathrm{C}, \mathrm{N})-1201(\mathrm{n}=1)$ and $1212(\mathrm{n}=2)$, ordering scheme of $-\mathrm{Cu}-\mathrm{C}(\mathrm{N})-\mathrm{C}(\mathrm{N})-\mathrm{C}(\mathrm{N})-\mathrm{Cu}-$ with four-times periodicity is observed in the charge-reservoir blocks (CRB), as shown in Fig.1(a) to (d) for $n=2$ compound. For $(\mathrm{Cu}, \mathrm{C}, \mathrm{N})-1234(\mathrm{n}=4)$, with highest $\mathrm{T}_{\mathrm{c}}$ of $113 \mathrm{~K}$ in the series, the ordering scheme of $\mathrm{Cu}-\mathrm{C}(\mathrm{N})-\mathrm{Cu}-\mathrm{C}(\mathrm{N})-\mathrm{Cu}-$ with twice periodicity is observed in the CRB. In the last two members, $(\mathrm{Cu}, \mathrm{C}, \mathrm{N})-1245(\mathrm{n}=5)$ and $1256(\mathrm{n}=6)$, no evidence of ordering was observed, suggesting that $\mathrm{Cu}, \mathrm{C}$ and $\mathrm{N}$ are distributed almost randomly in the CRB. Such relations between the order/disorder scheme and n-parameters, are also preserved locally in the crystals which contain plenty of intergrowth defects.

\section{Direct Observations of Ferromagnetic Domains in Manganites ${ }^{8)}$}

Ferromagnetic domains in $\mathrm{Nd}_{1 / 2} \mathrm{Sr}_{1 / 2} \mathrm{MnO}_{3}$, which undergoes the ferromagnetic to charge-order (antiferromagnetic) transitions at around $\mathrm{T}_{\mathrm{CO}}=150 \mathrm{~K}$, are examined by Lorentz TEM using mainly the Fresnel-mode. On cooling from paramagnetic state of room temperature, magnetic domain walls started to appear, as black and white lines, below $\mathrm{T}_{\mathrm{C}}=250 \mathrm{~K}$. The direction of magnetization in each domain is along the long sides of domain, suggesting that the compound has a magnetocrystalline anisotropy. With a further decrease of temperature, the volume of magnetic domains increased with discontinuous domain-wall jumps, and then gradually disappeared below $T_{\mathrm{CO}}=150 \mathrm{~K}$. Clear satellite reflections due to lattice distortion, are observed in the hk0 electron diffraction pattern. On heating process, a characteristic granular contrast with $30-40 \mathrm{~nm}$ in size was observed at around $140 \mathrm{~K}$, close to the $T_{\mathrm{CO}}$, as shown in the Lorentz TEM image in Fig. 3(a) and (b), at underfocus and overfocus, respectively. Such a granular contrast was not observed in the cooling process. We consider that the origin of this contrast is the formations of ferromagnetic microclusters in antiferromagnetic matrix. 


\section{References:}

1.) J.G. Bednorz and K.A. Muller, Z. Phys. B $\underline{64}$, 189, (1986).

2.) K. Chabara et al., Appl. Phys. Lett., $\underline{63}, 1990$ (1993).

3.) Y. Matsui et al., Ultramicroscopy, 39, 8, (1991).

4.) Y. Matsui and J. Akimitsu, Microsc. Res. and Tech., 30, 155, (1995).

5.) Y. Anan et al., Phil. Mag. B $\underline{81}, 1847$, (2001).

6.) T. Asaka et al., Phys. Rev. Lett., in press.

7.) T. Nagai et al., Phys. Rev. B., in press.

8.) T. Asaka et al., unpublished.
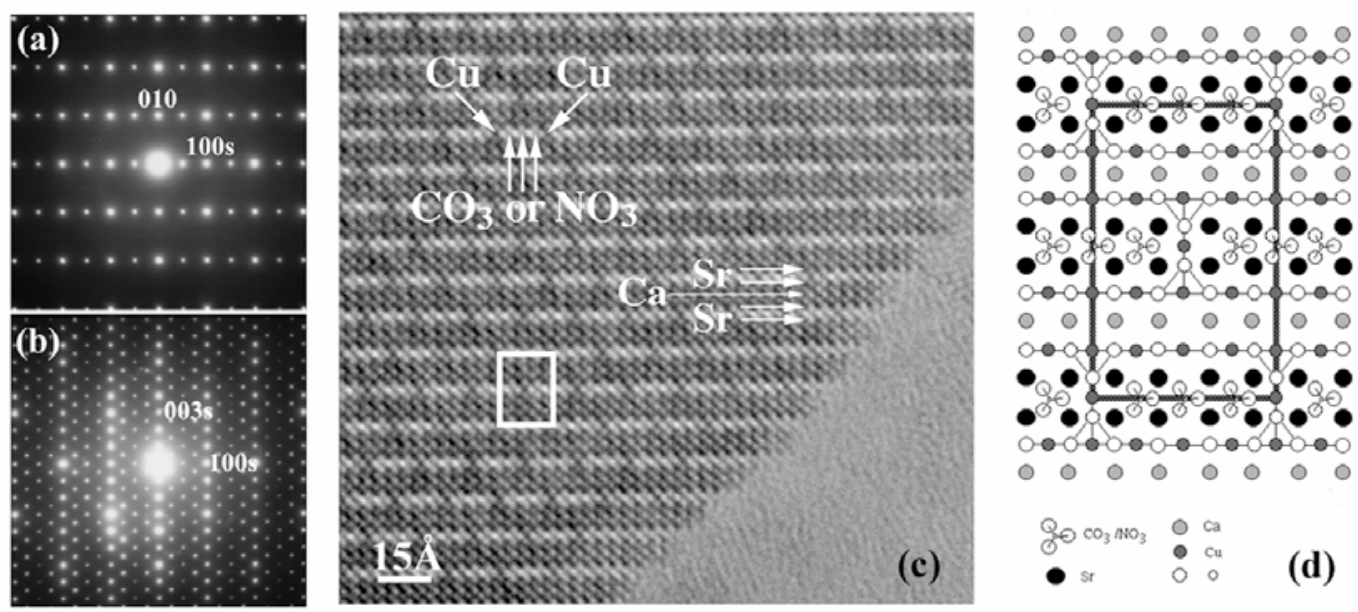

Fig. 1. The (a) $h k 0$ and (b) $h 0 l$ electron diffraction patterns, (c) HRTEM image projected along $b$ direction and (d) the superstructure model of $(\mathrm{Cu}, \mathrm{C}, \mathrm{N})-1212$ type of oxycarbonitrate superconductor. Ordered arrangements of $\mathrm{Cu}$ and three $\mathrm{CO}_{3}$ (partly $\mathrm{NO}_{3}$ ones) are clearly observed. HRTEM image was taken at $800 \mathrm{kV}$, by H-1500, to prevent electron-beam damage.
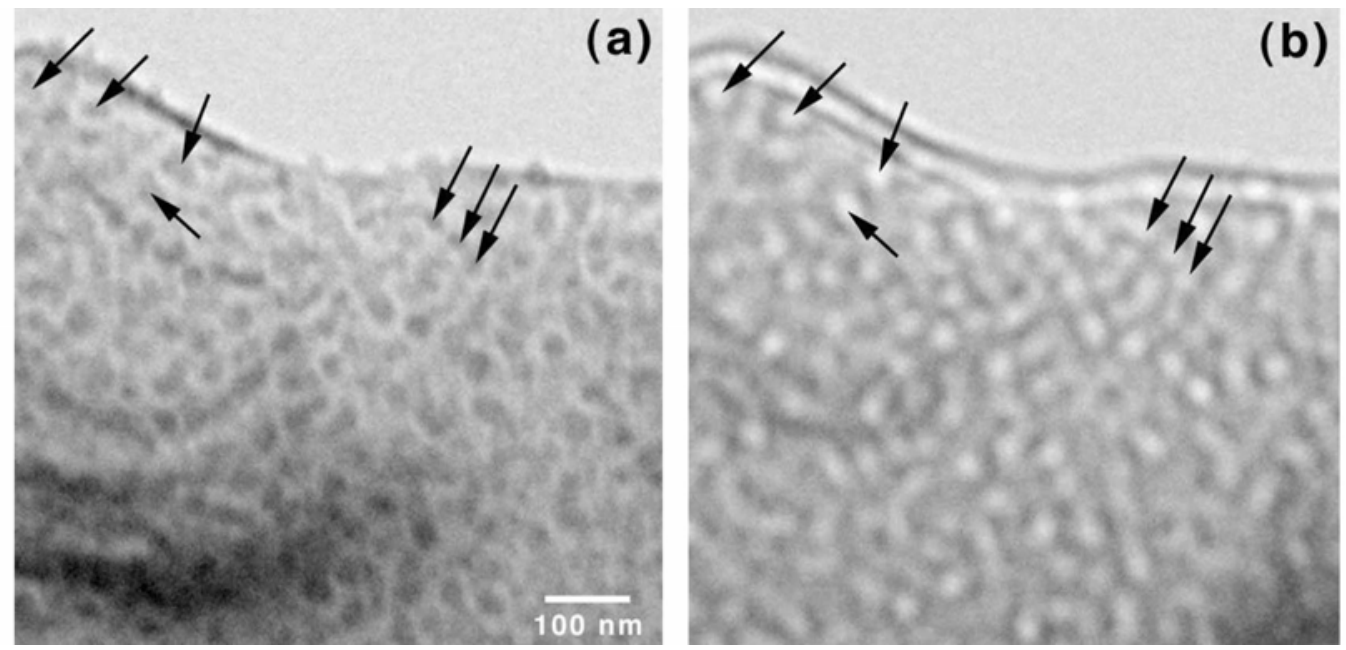

Fig. 2. Lorentz TEM images $(300 \mathrm{kV})$ of $\mathrm{Nd}_{1 / 2} \mathrm{Sr}_{1 / 2} \mathrm{MnO}_{3}$ in the (a)underfocused and (b)overfocused conditions at $140 \mathrm{~K}$, near $T_{\mathrm{CO}}$. Arrows indicate the reverse in contrast. 